Cite this article as: Kumar, P., Mulheron, M., Claudia, S., 2012. Release of ultrafine particles from three simulated building activities. Journal of Nanoparticle Research 14, 771, DOI: 10.1007/s11051-012-0771-2

\title{
1 Release of ultrafine particles from three simulated building 2 processes
}

3 Prashant Kumar ${ }^{\text {a, b, * }}$, Mike Mulherona, Claudia Som ${ }^{\mathrm{c}}$

$4 \quad{ }^{a}$ Division of Civil, Chemical and Environmental Engineering, Faculty of Engineering and 5 Physical Sciences (FEPS), University of Surrey, Guildford GU2 7XH, United Kingdom

$6 \quad{ }^{\mathrm{b}}$ Environmental Flow (EnFlo) Research Centre, FEPS, University of Surrey, Guildford 7 GU2 7XH, United Kingdom

$8{ }^{\mathrm{c}}$ Empa, Swiss Federal Laboratories for Materials Science and Technology, Technology

9 and Society Laboratory, Switzerland

\section{ABSTRACT}

11 Building activities are recognised to produce coarse particulate matter but less is 12 known about the release of airborne ultrafine particles (UFPs; those below $100 \mathrm{~nm}$ 13 in diameter). For the first time, this study has investigated the release of particles 14 in the 5-560 $\mathrm{nm}$ range from three simulated building activities: the crushing of 15 concrete cubes, the demolition of old concrete slabs, and the recycling of concrete 16 debris. A fast response differential mobility spectrometer (Cambustion DMS50) 17 was used to measure particle number concentrations (PNC) and size distributions 18 (PNDs) at a sampling frequency of $10 \mathrm{~Hz}$ in a confined laboratory room providing 19 controlled environment and near-steady background PNCs. The sampling point 20 was intentionally kept close to the test samples so that the release of new UFPs 21 during these simulated processes can be quantified. Tri-modal particle size 22 distributions were recorded for all cases, demonstrating different peak diameters 23 in fresh nuclei $(<10 \mathrm{~nm})$, nucleation $(10-30 \mathrm{~nm})$ and accumulation $(30-300 \mathrm{~nm})$ 24 modes for individual activities. The measured background size distributions 25 showed modal peaks at about 13 and $49 \mathrm{~nm}$ with average background PNCs $\sim 1.47 \times 10^{4} \mathrm{~cm}^{-3}$. These background modal peaks shifted towards the larger sizes during the work periods (i.e. actual experiments) and the total PNCs increased between 2 and 17 times over the background PNCs for different activities. After adjusting for background concentrations, the net release of PNCs during cube crushing, slab demolition, and "dry" and "wet" recycling events were measured as $\sim 0.77,19.1,22.7$ and $1.76\left(\times 10^{4}\right) \mathrm{cm}^{-3}$, respectively. The PNDs were converted into particle mass concentrations (PMCs). While majority of new PNC release was below $100 \mathrm{~nm}$ (i.e. UFPs), the bulk of new PMC emissions were constituted by the particles over $100 \mathrm{~nm} ; \sim 95,79,73$ and $90 \%$ of total PNCs, and $\sim 71,92,93$ and $91 \%$ of total PMCs, for cube crushing, slab demolition, dry recycling and wet recycling, respectively. The results of this study firmly elucidate the release of UFPs and raise a need for further detailed studies and designing health and safety related exposure guidelines for laboratory workplaces and operational building sites.

40 KEY WORDS: Ultrafine particles; Cement and concrete; Building activities; 41 Number and mass distributions; Construction nanoparticles exposure; 42 Environment, health and safety risks; Workplace air quality

*Corresponding author: Civil Engineering (C5), Tel. +44 1483 682762; fax: +44 1483 682135; Email addresses: P.Kumar@ surrey.ac.uk, Prashant.Kumar@ cantab.net (Prashant Kumar) 


\section{INTRODUCTION}

When concrete structures approach the end of their useful life, they can require extensive building works such as refurbishment and strengthening or even demolition and replacement through new construction. All such building activities are known to release significant amounts of coarse particles into the local environment. For instance, Dorevitch et al. (2006) found a 74\% increase in $\mathrm{PM}_{10}$ (particulate matter with $\leq 10 \mu \mathrm{m}$ aerodynamic diameter) concentrations $100 \mathrm{~m}$ downwind of a high-rise building demolition site in Chicago, USA. Likewise, Fuller et al. (2002) showed that fugitive $\mathrm{PM}_{10}$ emissions produced from building works at Marylebone Road in London during September 1999 contributed to daily mean $\mathrm{PM}_{10}$ concentrations in excess of $50 \mu \mathrm{g} \mathrm{m}^{-3}$. In a subsequent publication, the same authors reiterated that local fugitive $\mathrm{PM}_{10}$ episodes arising from building and road works in London and south east England can cause daily mean $\mathrm{PM}_{10}$ concentrations to exceed $50 \mu \mathrm{g} \mathrm{m}^{-3}$, breaching the EU limit value (Fuller and Green 2004). However, there are limited studies that quantify the release of ultrafine particles (UFPs; those below $100 \mathrm{~nm}$ in diameter) that arise from building works. A rare study on this topic by Hansen et al. (2008) found UFP concentrations in the vicinity of an old four-story reinforced concrete hospital building undergoing demolition to increase by up to 1.6 times. The UFPs produced during the demolition of such structures have the potential to carry airborne pathogens or viruses into the surrounding environment, including schools and densely populated residential or commercial areas. This is of some concern as currently there is very little documented about the release of UFPs from building activities associated with concrete structures and their subsequent redistribution both within, and across, the surrounding infrastructure.

The hydration of Portland cement is known to produce a series of hydrates silicate structures at the nanoscale which are characterised by having a extremely high surface area and associated multi-scale, inter-connected, pore system (McDonald et al. 2007). The fracture of these complex hydrated silicates within cement paste (and also some aggregates) during the demolition, refurbishment and recycling of concrete structures has the potential to release nano-sized particles of a range of potentially reactive aluminosilicates. Such processes appear to be poorly understood and require targeted studies. Recent trends to incorporate carbon nanotubes and plasticizers (e.g. nano-silica, $\mathrm{Fe}_{2} \mathrm{O}_{3}, \mathrm{SiO}_{2}, \mathrm{TiO}_{2}$ ) within a concrete mix to improve workability, pore structure, thermal behaviour, compressive and flexural strengths (Mann 2006; Nazari and Riahi 2011) introduce additional sources of UFPs within the structure of the cement paste and have been reviewed by Sanchez and Sobolv (2010). Thus, besides the usual emissions due to the fracture of conventional concrete, which is the topic of this study, the nanomodifications incorporated into the concrete mixes may also become airborne during construction, transport, storage or demolition (BystrzejewskaPiotrowska et al. 2009). It is important to note that the physical and chemical characteristics of UFPs produced during the processing of concrete structures are likely to differ from other airborne UFPs which are mainly produced from the combustion of fossil fuels in vehicles or industries (Kumar et al. 2010a; Kumar et al. 2011a). As a consequence, exposure to UFPs arising from building activities may have a different effect on both public health and the environment than UFP that arise from combustion (Kumar et al. 2010b). 
92 Guidelines from the International Labour Organisation (ILO 1995) and national

93 Governments, such as the Health and Safety Act at Work (The Stationary Office

94 1974), place a duty on employers to provide adequate protection to workers

95 undertaking building and demolition activities. Despite the common nature of

96 these activities, there is neither very much known about the types of UFPs

97 generated from building activities nor do any health and safety regulations

98 currently exist to limit their emission and associated exposure levels. An obvious

99 exception to this is the routine monitoring of asbestos during demolition and

100 refurbishment activities; the presence of which activates special methods of

101 decommissioning and subsequent handling of the generated waste stream (The

102 Stationary Office 1974).

103 Several review studies have appeared in the recent past to suggest strategies to 104 measure and analyse the airborne UFP data within the workplace (Brouwer et al. 105 2009) and support the development of benchmark levels (Brouwer 2010). A 106 variety of personal exposure sources of UFPs such as laser printers (McGarry et 107 al. 2011), cooking activities (Buonanno et al. 2009), driving, operating small 108 appliances such hair dryers, cigarette smoke and eating at restaurants and cooking 109 in kitchen (Wallace and Ott 2011) have also been investigated in great detail by 110 recent research articles. There have also been comprehensive reviews of various 111 UFP related aspects such as measurements (Kumar et al. 2010b), dispersion 112 modelling (Kumar et al. 2011b), technical regulatory challenges (Kumar et al. 113 2011c; Kumar 2011d), ambient and commuters' exposure to UFPs (Knibbs et al. 114 2011; Morawska et al. 2008), besides exposure at nanotechnology workplaces 115 (Kuhlbusch et al. 2011). There remains, however, no mention of building 116 activities produced UFPs and related exposure.

117 Given the scarcity of information on this topic, the investigation of the release of 118 UFPs from construction processes is crucial for the following reasons: (i) 119 assessing the source strength and exposure of people working at building sites or 120 living (and travelling) in their close vicinity, (ii) analysing the impacts of UFPs arising from building activities on local air quality, (iii) to provide regulatory bodies with information for setting safe guidelines for activities involved in construction, renovation and demolition of concrete structures, and (iv) determining the penetration of UFPs arising from building activities into nearby indoor shelters (e.g. residential and commercial buildings, and sensitive areas such as hospital and schools). This article investigates the release and physical characteristics of particles during the crushing of concrete, demolition of concrete slabs, and recycling of "dry" and "wet" concrete debris by means of a laboratory study. UFPs related health and safety implications at the laboratory workplaces and building sites are also discussed. Note that the focus of this article is on particle numbers for determining the emissions rates from selected sources and processes. Chemical characterisation or the quantification of exposure doses is not the primary aim of this work.

\section{MATERIALS AND METHODS}

\subsection{Instrumentation}

Experiments were carried out at the University of Surrey's Construction

137 Materials Laboratory. A fast response differential mobility spectrometer 138 (Cambustion DMS50) was used to measure number and size distributions of 139 particles, released during three simulated building activities undertaken on 140 samples of hardened concrete manufactured from three standard Portland cement 
141 concrete mixes. The three test arrangements used were: (i) the compressive failure 142 of concrete (cubes) under progressive loading, (ii) the demolition of concrete slabs 143 under (simulated) impact load, and (iii) the processing of concrete debris to 144 produce recycled concrete aggregate. During each test, the DMS50 measured particles in the 5-560 $\mathrm{nm}$ range in 32 size channels. This size range is of interest and generally comprises over $99 \%$ of particles by number in the ambient environment (Kumar et al. 2008b; Kumar et al., 2009). Unlike other similar instruments reviewed by Kumar et al. (2010b), the DMS50 is one of the fastest, commercially available, portable, both DC and AC operatable, particle spectrometers and has been successfully deployed in previous experiments (Carpentieri and Kumar 2011). The DMS50 uses a sampling flow rate of 6.5 lit $\min ^{-1}$ which is maintained by an electric pump and a classifier restrictor located within body of the instrument. The main limitation of the instrument is the largest size range measured, but this is not a concern in these experiments as the measurements focus mainly on particle numbers and desired size range is covered. The instrument uses a differential mobility classifier that provides a sampling frequency up to $10 \mathrm{~Hz}$, with a time response $\left(\mathrm{T}_{10-90 \%}\right)$ equal to $500 \mathrm{~ms}$, without the inlet tube. Therefore, the use of the DMS50 offered an opportunity to measure size resolved particle number and size distributions in real time under non-steady state conditions. The highest sampling frequency available with the DMS50 was used for measurements since the particle emission events during experiments typically lasted for only few seconds (see Section 3). The DMS50 measures particle diameters based on the electrical mobility detection technique which provides equivalent diameter of a particle after implicitly taking into account their shape and size. The instrument was calibrated by Cambustion Ltd. in July 2010 and the experimental duration was within the calibration validity period of 12 months. A $0.25 \mathrm{~m}$ long thermally conductive sampling tube, made of silicon rubber and having $0.0055 \mathrm{~m}$ internal diameter, was used to connect the DMS50 and the sampling location for the experiments described in Section 2.2. Sampling flow rate was kept to $6 \mathrm{slpm}$ with a line pressure of $80 \mathrm{kPa}$. Losses of particles due to diffusion within the sampling tubes were neglected considering its small length (Kumar et al. 2008c). Detailed descriptions of the working principle and the application of DMS50 for ambient measurements can be found in Kumar et al. (2010b), and Carpentieri and Kumar (2011). Over the duration of the experiments, the average ambient temperature and relative humidity $(\mathrm{RH})$, measured using a LaCrosse WS-2350 weather station, was found to be $18 \pm 1{ }^{\circ} \mathrm{C}$ and $60 \pm 2 \%$, respectively.

178 The testing of the concrete cubes was undertaken using a Farnell, 200 Tonnes 179 capacity, standard cube compression testing machine (BS EN 12390-4:2000 180 2000). The cubes were loaded through steel sub-platens at constant rate until 181 failure (BS EN 12390-3:2009 2009). Three loading rates were employed for 182 assessing the sensitivity of UFPs produced during the stress applied to concrete 183 cubes: P1 $\left(120 \mathrm{kN} \mathrm{min}^{-1}\right), \mathrm{P} 2\left(240 \mathrm{kN} \mathrm{min}^{-1}\right)$ and P3 $\left(360 \mathrm{kN} \mathrm{min}{ }^{-1}\right)$. Demolition 184 of the concrete slabs was carried out using standard hand tools to simulate the 185 impact hammer method of demolition (Blake 1989). To simulate some of the 186 processes that occur during recycling samples of concrete debris were processed 187 using a standard rotating drum mixer with both fixed and floating arms.

\subsection{Samples and experimental set up}

Testing was undertaken on samples of hardened concrete manufactured from 190 three cement concrete mixes, M1 (Grade C35/45), M2 (Grade C30/37) and M3 
(Grade C25/30), incorporating a CEM Type I Portland cement (42.5) and a flinty river gravel aggregate (see details in Table 1). These mixes were selected to represent the typical strength range, and properties, of normal concrete mixes that might be encountered in conventional reinforced concrete buildings. It should be noted that no admixtures of any kind were employed in the manufacture of the concrete used in this study. A total of 13 samples were used during the three tests:

(i) Three $(100 \times 100 \times 100 \mathrm{~mm})$ concrete cubes were manufactured from each of the mixes M1, M2 and M3 using standard methods (BS EN 12390-2:2009 2009) and the resulting nine cubes were cured for 42 days at $100 \% \mathrm{RH}$ and $20{ }^{\circ} \mathrm{C}$. The cubes were tested to failure in compression under progressive loading at loading rates $\mathrm{P} 1, \mathrm{P} 2$ and $\mathrm{P} 3$. These samples were designated as M1P1, M1P2, M1P3, M2P1, M2P2, M2P3, M3P1, M3P2, and M3P3; with M1-3 and P1-3 referring to the strength grade and loading rate, respectively. A rectangular steel case was placed around the cubes crushing area of the compression testing machine to help prevent any fugitive particles from coming into the casing area. The head of the sampling tube was kept at $0.05 \mathrm{~m}$ away from the cube surface to measure the source emissions in the form of particle number and size distributions produced.

(ii) Simulated demolition was carried out on two $1000 \times 500 \times 50 \mathrm{~mm}$ fully compacted plain concrete slabs manufactured from mix M2 that had been cured at $100 \% \mathrm{RH}$ and $20{ }^{\circ} \mathrm{C}$ for 28 days and subsequently stored in laboratory air for 8 months at $50-75 \% \mathrm{RH}$ and $19 \pm 2{ }^{\circ} \mathrm{C}$. The slabs were placed, in turn, on wooden supports at their ends and subject to impact at their centre point using a hand-held "lump" hammer. This caused immediate failure of each slab into two parts each of which were then broken into smaller sections. The head of the DMS50 sampling tube was placed at $0.05 \mathrm{~m}$ above the centre of the slab for measuring the release of UFPs simultaneously with the demolition process.

(iii) Debris from the crushed concrete cubes and broken slabs (described above) was mixed with $\approx 25 \mathrm{~kg}$ of recycled concrete aggregate (with a particle size in the range 5-20 mm) obtained from a commercial processing plant. To simulate some of the processes that occur during the recycling process the combined "dry" material was placed into a standard rotating drum mixer. The mixer was then operated at a speed of $\approx 20 \mathrm{rpm}$ and the levels of PNCs produced monitored. Subsequently, $\approx 4 \mathrm{~kg}$ of water was sprayed over the surface of the aggregate and the experiment was repeated to determine the UFPs produced when processing the "wet" material. Simultaneous measurements of number and size distributions of particles were made during both experiments by placing the head of the sampling tube at $0.15 \mathrm{~m}$ above the mixer's perforated lid.

For all the tests, selection of an appropriate location of the sampling point was crucial as this can appreciably change the amount of measured PNCs. Earlier studies have demonstrated that number concentration and size distributions of particles may vary with distance to the source due to effect of transformation processes (e.g. nucleation, coagulation, condensation, deposition) (Kumar et al. 2011b), limiting the reliability of estimates for personal exposure assessments (Brouwer 2010; Brouwer et al. 2004). Since the aim of this work was to 
investigate the release of new UFPs during the processing of concrete but not their spatial dispersion into the surrounding environment or the exposure assessment,

243 the measurement points were kept as close as possible to the samples so that the into the ambient environment can be captured. It should also be noted that this work aimed to investigate three simulated building processes (crushing, demolition and recycling) using conventional Portland cement concrete samples representative of that encountered in real structures. None of the samples used in this study included any commercial additives and so the influence of concrete admixtures on the release of UFPs is not considered in this work.

\subsection{Estimation of particle mass distributions (PMDs) and concentrations (PMCs)}

The PMDs $\left(\mathrm{d} M / \mathrm{d} \log D_{\mathrm{p}}\right)$ are estimated by multiplying the measured PNDs $\left(\mathrm{d} N / \mathrm{d} \log D_{\mathrm{p}}\right)$ with the mass per particle $M\left(D_{\mathrm{p}}\right)$ (Park et al. 2003) based on the mobility diameter, $D_{\mathrm{p}}$, as seen in Eq. (1) below:

$$
\frac{d M}{d \log D_{p}}=M\left(D_{p}\right) \frac{d N}{d \log D_{P}} \quad \text { and } \quad M\left(D_{p}\right)=\frac{\pi}{6} D_{P}^{D f} \rho
$$

Where $\rho\left(=2.3 \mathrm{gm} \mathrm{cm}^{-3}\right)$ is particle density which is assumed same as the density of a typical standard mix of concrete and $\mathrm{D} f$ is the fractal dimension of particles. Generally, the particles are not expected to be in ideal spherical shape and their volume is no longer proportional to $D_{\mathrm{p}}{ }^{3}$, therefore a typical value of $\mathrm{D} f(=2.34)$ is adopted from the experiments of Park et al. (2003). The obtained $\mathrm{d} M / \mathrm{d} \log D_{\mathrm{p}}$ in each of 32 size bins were further integrated and summed up for obtaining PMCs $\left(\mu \mathrm{g} \mathrm{cm}^{-3}\right)$ in desired size ranges (Kumar et al. 2008b).

\section{RESULTS AND DISCUSSION}

\subsection{Release of UFPs during the crushing of concrete blocks}

Contours of particle number distributions (PNDs) obtained during the crushing of the three different strength concrete cubes (M1, M2 and M3) at varying loading rates (P1, P2 and P3) did not show any distinctive evidence of new particle release (see Supplementary Information, SI, Figure S.1). These did however show higher density for $\sim 5$ and $50 \mathrm{~nm}$ size particles. We investigated this further to distinguish the effect of individual concrete blocks on number and size distributions and plotted average PNDs during the crushing of each sample with the background PNDs (Figure 1). Here and in subsequent tests, the background PNDs were distinguished using the time series approach assuming that the concentration measured during no-work activity is the background and any increase during the work activity reflects new particle release (Kuhlbusch et al. 2011). This assumption applies well to our measurements as the experiments were conducted in a confined laboratory environment where significant changes in background PNDs were not expected over a relatively short sampling duration. Therefore, concentrations during the no-work activity were monitored at the beginning of the each test until the stabilised levels of background PNDs were achieved.

All the PNDs showed similar shapes, peaking at about 5.6, 11.5 and $48.7 \mathrm{~nm}$, respectively (Figure 1). There was an increase in both the nucleation $(<30 \mathrm{~nm})$ and accumulation $(>30 \mathrm{~nm})$ mode particles above the background levels during 
287 individual crushing events. Total PNCs averaged over the crushing events of all 9 288 samples in the 5-560 nm size range were measured as $2.27 \pm 0.41 \times 10^{4} \mathrm{~cm}^{-3}$, with 289 a background contributions of about $1.47 \times 10^{4} \mathrm{~cm}^{-3}$. If we divide them into various 290 size bins, average PNCs over the all crushing events were $~ 37,55$ and $27 \%$ higher 291 than the background PNCs in the 5-10, 10-30 and 30-300 nm size ranges, 292 respectively. In all cases (background, total average over all events, and net after 293 subtracting background) the majority ( 95\%) of total PNCs were found in the 294 UFP size range $(<100 \mathrm{~nm})$. If we subtract the background fraction from the 295 average PNCs over the all crushing events, the remaining particles should reflect 296 the quantity of new particles release during the crushing process. Such a release in 297 the 5-100, 100-300 and 300-560 nm size ranges constituted $~ 94.8,4.8$ and $0.4 \%$, 298 respectively, of total averaged PNCs in the 5-560 nm size range $\left(\sim 0.77 \pm 0.50 \times 10^{4}\right.$ $299 \mathrm{~cm}^{-3}$ ). These observations clearly indicate that the majority of particles were 300 generated in the UFP size range.

301 It had originally been expected that a greater release of UFPs would be produced 302 as the rate of loading and concrete strength increased. However, a more complex 303 picture emerged with the PNDs increasing with decrease in loading rate for cubes 304 manufactured from the highest strength mix (M1) while an opposite trend was 305 seen for the cubes manufactured from the lowest strength mix (M3) (Figure 1). This may reflect the different failure modes observed for the M1 and M3 mixes and maximum load (stress) they sustained. The concrete cubes manufactured from the lowest strength mix (M3) were observed to fail non-explosively by Poisson splitting with the predominant failure mode being debonding at the aggregate/cement interface with little sign of failure of the individual aggregate particles. This was expected given both the nature of the aggregate used, which was a relatively smooth surfaced river gravel, and the high water/cement ratio (0.55) of the cement paste that acted together to limit the maximum stress that the concrete could sustain without failure to $30-36 \mathrm{~N} \mathrm{~mm}^{-2}$. In contrast, the cubes manufactured from mix M1 tended to fail explosively with aggregate failure being the main mode of failure with clear evidence of debonding at the aggregate/cement interface occurring only at the lower loading rate (P3). The failure stress carried by the M1 concrete cubes was between $51-57 \mathrm{~N} \mathrm{~mm}^{-2}$ and, as expected, increased with loading rate. This increased load capacity reflects the improved interaction between the aggregate and the hydrated cement resulting from the lower free water/cement ratio of the M1 mix (0.40). It may be noted that the cubes manufactured from the M2 mix showed "mixed" failure modes with a complex dependence on loading rate.

Looking at the results in Figure 1 in detail it can be seen that there are two main peaks of UFPs produced during the crushing of the concrete cubes: Peak (i) ( $D_{\mathrm{p}}=$ 5-6 nm) and Peak (ii) ( $D_{\mathrm{p}}=40-60 \mathrm{~nm}$, along with a side peak). The loading rate can be seen to influence the Peak (i) behaviour differently, i.e. decreasing for the M1 (high strength) mix and increasing for the M3 (low strength) mix. In contrast, Peak (ii) values for the M1 concrete mix are always higher than those for the M3 mix and in both cases are relatively independent of the loading rate. Thus, considering the failure modes of the cubes this suggests that Peak (ii) reflects processes associated with the explosive failure of the cubes and which are connected with fracture of the aggregate particles and associated failure of the cement paste. Peak (i) would appear to reflect processes that occur predominantly during debonding at the aggregate/cement interface perhaps with associated crack formation through the cement paste. 
337 The above observations generally indicate an increase in UFP concentrations, 338 with a relatively larger change in nucleation mode particles in comparison with 339 accumulation mode particles, during the crushing events (Figure 1). Whilst the 340 effect of loading rate and concrete strength on PNC release could not be 341 conclusively demonstrated the observed emissions seem to relate to failure mode. However, confirmation of this proposal would require further investigation on a larger number of samples. The findings do, however, carry an implication for those involved in the construction, repair and demolition of concrete structures in that the processes of compressive failure are capable of creating a different size range of particles depending on the strength grade and loading rates. This leads to the need for the protection of personnel exposure and improvements in construction practices (Section 3.5).

\subsection{Release of UFPs during demolition of concrete slabs}

Two concrete slabs, Slab-1 and Slab-2, were used to simulate the release of UFPs during their demolition through an impact hammer method (Blake 1989). Contour plots for each case showing their number and size distributions are plotted in SI Figure S.2. For analysing the number and size distributions of particles generated during the different stages of the experiment, the data here (and in Section 3.3) are divided into four sub-stages based on the temporal evolution of particles. These include: (i) background (just before the start of the experiments; no-work period), (ii) demolition events (during the actual time of impact demolition; work period), (iii) decay (starting just after the end of work period and ending when the concentrations become near steady; no-work period), and (iv) post-background (starting after the decay period when concentration decay becomes near steady; no-work period). These sub-stages are marked in SI Figures S.2 and S.3 but the concentrations measured during the first two substages (background and actual events) were of most interest to identify new release of UFPs and are considered below for detailed discussion.

The two slabs produced different quantities of PNCs during the demolition stage (i.e. $2.41 \times 10^{5}$ and $1.66 \times 10^{5} \mathrm{~cm}^{-3}$ ) but the physical characteristics of the contour plots (SI Figure S.2), the temporal pattern of PNC release (Figures 2a and b) and size distributions (Figures $2 \mathrm{c}$ and d) were very similar. For instance, a distinct rise in PNDs can be seen in both cases during the demolition process for both samples where the peak diameters were found at about 30 and $200 \mathrm{~nm}$, respectively (Figures 2c and d). Furthermore, in both cases peak PNCs increased by about 20 times during the demolition stage relative to the background PNCs (Figures 2 a and b) and then reverted back to post-background levels after a decay process of about $25 \mathrm{~s}$. The post-background stage exhibited an elevated level of PNCs relative to the background stage due to the accumulation of particles in the local background; the post-background stage lasted for 10's of seconds before returning back to background PNCs.

PNDs plotted for various stages in Figures $2 \mathrm{c}$ and $\mathrm{d}$ provide a clear indication of the release of particles in the UFP size range. Interestingly, the shape of PNDs remains the same for all the four stages, except for the changes in their magnitude. As expected, the highest PNDs were observed during the demolition stage, showing peak diameters at about 30 and $200 \mathrm{~nm}$. This was then followed by the PNDs in decay and post-background stage. One of the interesting observations from these plots is that the PND spectrum moves up and down without any appreciable changes in their modes and peak diameters during all stages. This 
negligible change in the shapes of modes indicates the influence of dilution controlling the magnitude of PNDs (Kumar et al. 2008b).

Another interesting aspect to analyse from these results is the changes in proportion of PNCs in various size ranges during different sub-stages. Depending on the PND modes shown in Figure $2 \mathrm{c}$ and $\mathrm{d}$, we divided the entire size range of particles into three ranges: 5-100 nm (i.e. UFPs), $100-300 \mathrm{~nm}$, and 300-562 nm (SI Figure S.3). Generally, particles over $300 \mathrm{~nm}$ were found to be modest (i.e. $\sim 1 \%$ of total PNCs) during all the sub-stages whereas particles in the 5-100 nm range dominated (up to 93\%) the total PNCs. Further, background PNCs were subtracted from the total PNCs to identify the release of new particles during the demolition stage. Average particle release in the 5-560 $\mathrm{nm}$ size range were estimated as $1.91 \pm 0.36 \times 10^{4} \mathrm{~cm}^{-3}$ with UFPs constituting over two third $(\sim 79 \%)$ of total PNCs.

Since there are no data available in the literature to directly compare our results, we have sought to put our results in perspective of the study by Hansen et al. (2008). They measured the particles in various size ranges nearby the demolition site of a hospital building and found UFP concentrations to increase by about 1.6 times above those before the demolition. If we average our PNCs over the demolition and decay periods and divide them by the background PNCs, this ratio for UFPs turns out to be 1.53 which is co-incidentally very similar to that reported by Hansen et al. (2008). This comparison is encouraging but requires further substantiation by means of laboratory investigation on a large number of samples and field measurements close to the building demolition sites, as described in Section 4.

\subsection{Release of UFPs during dry and wet recycling of concrete debris}

Contour plots showing PND spectrum (SI Figures S.4a and b) indicate differences in release of new particles during "dry" and "wet" recycling of concrete debris. As in Section 3.2, the experimental data were divided into four temporal sub-stages (background, recycling ("dry" and "wet"), decay and postbackground) to identify the UFPs released during recycling.

The use of water spraying is a common method for suppressing airborne dust particles during construction activities (Tjoe Nij et al. 2003). This method can suppress $\mathrm{PM}_{10}$ concentrations that occur during the demolition of buildings by up to 10 times (Kukadia et al. 2003). Studies have also shown a decrease in UFP concentrations with increasing relative humidity and, conversely, an increase in UFPs during dry weather conditions (de Hartog et al. 2005). This is further substantiated by the fundamental phenomena of UFP scavenging (rainout) due to rainfall (Andronache et al. 2006) and aerosol-hydrometer coagulation (washout) (Kumar et al. 2011b). Our results appears to compliment these observations since a significant difference was found between the total PNCs measured during "dry" $\left(2.51 \times 10^{5} \mathrm{~cm}^{-3}\right.$; SI Figure S.4a) and "wet" $\left(0.52 \times 10^{5} \mathrm{~cm}^{-3}\right.$; SI Figure S.5b) recycling. UFPs contributed to a major proportion of these particles; $1.88 \times 10^{5} \mathrm{~cm}^{-}$ 3 during "dry" recycling compared with $0.46 \times 10^{5} \mathrm{~cm}^{-3}$ during "wet" recycling. Similar to the other cases (Sections 3.1and 3.2), particles over $300 \mathrm{~nm}$ were found to be modest (i.e. $\sim 1 \%$ of total PNCs) during both recycling processes (SI Figure S.5). 
As expected during the temporal sub-stages, largest magnitudes of PNDs were found during "dry" recycling that was followed by decay and post-background stages (Figure 3c). Figure 3d show a clear picture of suppressed PNDs over the all size ranges during "wet" recycling as opposed to "dry recycling" (Figure 3c).

440 Particle diameters peaked at about 40 and $200 \mathrm{~nm}$ during the "dry" recycling whereas these peaks shifted to about 30 and $200 \mathrm{~nm}$, in addition to a $10 \mathrm{~nm}$ peak, during the "wet" recycling (Figure 3d). This additional peak at $\sim 10 \mathrm{~nm}$ during "wet" recycling indicates a transient nuclei mode, presumably developed due to the nucleation of sprayed water during rapid mixing (Kumar et al. 2011b). The slight shift of $40 \mathrm{~nm}$ peak diameter during "dry" recycling to $30 \mathrm{~nm}$ during "wet" recycling could well be due to the relative effect of coagulation processes as the PNCs during the latter event were up to an order of magnitude larger, and high enough to initiate rapid coagulation (Kumar et al. 2011b).

Peak PNCs increased to about 17 times against the background during the "dry" recycling (Figure 3a) compared with a modest increase ( 3 times) in peak PNCs during the "wet" recycling (Figure $3 b$ ). Subtraction of the background from the total PNCs during recycling events provided estimates of new particle release in addition to the indication of suppression effect of water spray on various size ranges of particles. New PNC release during the "wet" recycling was computed as $\sim 13$ times smaller $\left(1.76 \times 10^{4} \mathrm{~cm}^{-3}\right)$ than those found during "dry" recycling $\left(2.27 \times 10^{5} \mathrm{~cm}^{-3}\right)$. For both cases, majority of this release was in the ultrafine size range which constituted nearly two third $(\sim 73 \%)$ and $90 \%$ of total new PNCs during the "dry" and "wet" recycling processes, respectively. Particles in the 100 300 contributed about 26 and 9\% during "dry" and "wet" recycling, respectively, with only a modest $(\sim 1 \%)$ contribution by the $300-560 \mathrm{~nm}$ size range in both cases. The ratio of new PNCs release in the ultrafine size range $(5-100 \mathrm{~nm})$ to the remaining size range $(100-560 \mathrm{~nm})$ changed from $\sim 2.7$ during "dry" recycling to $\sim 8.7$ during "wet" recycling. The higher relative proportion of PNCs in the 5-100 size range with respect to larger size particles during "wet" recycling suggest that the latter are better suppressed by the water spray compared with UFPs (Kumar et 466 al. 2011b).

\subsection{The PMDs and corresponding PMCs generated by various processes}

Following the methodology presented in Section 2.3, the net PMDs are computed (Figure 4) after subtracting the background PMDs which correspond to background PNDs in Figures 1-3. Unlike the PNDs for various processes where up to $95 \%$ of total PNCs were below the $100 \mathrm{~nm}$ size range (Figures 1-3), the majority of contribution extending up to $93 \%$ came from the particles above 100 $\mathrm{nm}$ in size range (Figure 4). More precisely, this mass based contribution was 93, 92, 91 and $71 \%$ of total PMCs in the 5-560 nm size range for "dry" recycling, slab demolition, "wet" recycling and cube crushing, respectively (Figure 5). These results are in line with the observations reported for engine (Kittelson 1998), indoor (Wallace and Ott 2011) and ambient monitoring studies (Harrison et al. 2011; Kumar et al. 2010b; Kumar et al. 2011c) due to the fact that the tiny particles in the UFP size range possess negligible PMCs but notable PNCs. Also it can be argued that targeted mitigation measures are required for the UFPs produced from these activities since the mass based measures will not be effective to limit the exposure to building activities produced UFPs.

483 Closer inspection of the PMDs demonstrated bi-modal distributions for all the 484 four processes, showing a shrink in smaller, and the other over a magnitude larger, 
peak at about 65 and $274 \mathrm{~nm}$ in both modes, respectively, as opposed to the background peaks at about 78 and $300 \mathrm{~nm}$ (Figure 4). The PMDs were also found to be relatively similar in shape for each process which was not the case for the PNDs. As expected, the magnitude of each PMD spectrum followed the same demolition and cube crushing (Figures 1-3). No published studies could be located for direct comparison but these results can be put in the context of ambient studies for drawing interesting observations. For instance, Kumar et al. (2008b) measured the PNDs in the 5-2500 nm size range in an urban street canyon and converted them into the PMDs which showed two peaks at about 237 and $649 \mathrm{~nm}$. The shapes of the PMDs in these two studies were different, with an additional peak in UFP size range at about $65 \mathrm{~nm}$ in current study, reconfirming the emissions of new particles in the UFP size range.

\subsection{Implications of results towards health and safety regulations}

The ILO uses the concept of "decent work" for all workers with temporary or formal employment deployed at building sites (ILO 1995), though these guidelines do not include anything specific for UFP exposure. In Europe, the general framework is provided by the regulation on occupational safety and health of workers (EU Directive 89/391/EEC; Directive 98/24/EC) and under the REACH (Registration, Evaluation, Authorization and Restriction of Chemicals) framework. This framework includes guidelines for risk assessments related to synthesis, handling and transport of nanomaterials at workplaces but do not include anything relevant to UFPs arising from construction materials. In view of the above, various countries have set out their own guidelines to control exposure at operational building sites. For instance, the Building and Research Establishment (UK) provides specific guidance for dust particles and $\mathrm{PM}_{10}$ that may become airborne (Kukadia et al. 2003). They can carry deposited biological debris (e.g. fungal spores, moulds, bird droppings or aspergillus) on the building surfaces during the demolition via explosives, demolition ball, sledge and jack hammers or other demolition plan and equipment if appropriate control measures are not adopted (Kukadia et al. 2003). Furthermore, the Health and Safety Executive provide guidelines for very fine dust such as respirable crystalline silica (RCS) for the use of cut-off saws during construction; exposure to RCS can cause serious health effects such as lung cancer or silicosis and its 8-hour time averaged exposure limit at workplaces is kept to $0.1 \mathrm{mg} \mathrm{m}^{-3}$ (HSE 2010). Exposure to other hazardous substances, including RCS, at the workplaces is controlled through the control of Substances Hazardous to Health regulations (COSHH 2005). Currently, however, there is no international or local guidance for controlling the release and exposure of UFPs at buildings sites. There is a HSE Research Report on the assessment of different metrics of the concentration of nano (ultrafine) particles in existing and new industries (HSE 2006) but this limit its scope to UFP exposure in industrial work places. Moreover, current control measures in terms of exposure limits for dust particles or RCS are based on mass concentrations which is not appropriate for UFPs as they carry negligible PMCs (Kumar et al. 2008a).

Physicochemical characteristics of particles, especially produced from buildings activities, can be substantially different in terms of their size distributions (Sections 3.1-3.3), shape, morphology, chemical composition, oxidant potential and toxicity than other nanoparticles, mainly produced from the combustion of fossil fuels (Kumar et al. 2010a; Nowack and Bucheli 2007). Even a small increase in PNCs originating from concrete demolition might have negative health 
effects to the people exposed at workplaces, operation building, demolition or renovation sites, or in surrounding areas, though allied health effects are still needed to be established. Building activities has been initially thought of as being source of particles in the $\mathrm{PM}_{2.5}$ and the $\mathrm{PM}_{10}$ ranges. Our study identified the UFP generation which is likely to occur during demolition and related construction activities in community settings. The levels of new UFP release (in the order of $\sim 10^{4}-10^{5} \mathrm{~cm}^{-3}$ ) identified here are not trivial and exposure can increase appreciably if these occur for longer durations as would be the case in typical operational situations. Thus, workers and at-risk communities may require additional respiratory protection than would be needed if only coarse particulates were generated. Also there is a need for the production of appropriate guidelines for those involved in such activities.

\section{SYNTHESIS AND FUTURE RESEARCH CHALLENGES}

This study presents the preliminary estimates of UFP release during the crushing of concrete cubes, demolition of concrete slabs and recycling of concrete debris. Particle size distributions were measured simultaneously in the 5-560 nm size range close to the test samples to estimate the emission strengths of various simulated building activities. The results are discussed in terms of both number and mass distributions of particles and implications associated with the health and environment at laboratory workplaces and at operational building sites.

The shapes of PND spectrums for each activity were distinctly different from each other, except for a consistent and unchanged small peak in all cases at about 5.6 $\mathrm{nm}$, with the other two background modal peaks at 13 and $49 \mathrm{~nm}$ diameters. Detailed inspection of modal peaks during work against the background indicate that cube crushing produced relatively fine particles (with modal peaks at $\sim 11.5$ and $49 \mathrm{~nm})$, followed by slab demolition $(\sim 20$ and $300 \mathrm{~nm})$, "wet" recycling $(\sim 30$ and $200 \mathrm{~nm}$, with an additional small peak at about $10 \mathrm{~nm}$ ) and "dry" recycling ( 40 and $200 \mathrm{~nm}$ ). The total PNCs increased about 2, 3, 14 and 17 times over the backgrounds during cube crushing, "wet" recycling, slab demolition and "dry" recycling respectively. The releases of new particles during individual events were estimated by subtracting the background PNCs from the total PNCs obtained during an event. These releases were found to be $\sim 0.77,19.1,22.7,0.18\left(\times 10^{4}\right)$ $\mathrm{cm}^{-3}$ during cube crushing, slab demolition, "dry" and "wet" recycling events, respectively. The majority of new particle emissions were detected in the ultrafine $(<100 \mathrm{~nm})$ size range, contributing $\sim 95,79,73$ and 90\% of total PNCs for cube crushing, demolition, "dry" and "wet" recycling events, respectively. Furthermore, particle release in the $100-300 \mathrm{~nm}$ size range during these events corresponded to $\sim 4,19,26$ and $9 \%$, respectively, leaving a modest fraction $(\sim 1 \%)$ of particles over $300 \mathrm{~nm}$ size range.

580 the major fraction of PMCs stayed over the $100 \mathrm{~nm}$ size range and reverse was the

581 case for the PNCs. 
The study also has its explainable limitations. Firstly, it can be argued that laboratory simulations do not represent the real operational conditions at building sites. The second related argument can be the generalisation of results for real world conditions. As discussed earlier, this was unclear at the first place whether such activities produce UFPs and if yes then how much proportions in various particle size ranges. Investigating this uncultivated source, confirmation of UFP release, preliminary quantification of their concentrations and outlining a transferable methodology in itself justifies this work. Furthermore, the release rates estimated through laboratory studies, such as here, are important for workplace modelling and offer a complimentary route to derive possible exposure to UFPs (Kuhlbusch et al. 2011; Schneider et al. 2011), besides providing base information for designing detailed studies at operational building sites. Such laboratory studies are also essential to assess the potential risks, especially in cases when there is rarely any published literature available on a topic like the one covered here.

Besides the above, this work has also opened up a number of novel questions for further inter-disciplinary research to envisage related mitigation strategies. For example, measurements on a large number of samples, including concrete mixes with 'nanoparticles-based' admixtures (Sanchez and Sobolev 2010), are required to analyse the impact of admixtures on the rate of release and changes in physicochemical characteristics of released particles. Also, measuring PNCs at different locations during the testing can aid in mapping their spatial distributions and dispersion into the surrounding environment which could help facilitate exposure assessment in laboratory environments. There is also an equal need for field monitoring at building sites to link the results of various processes with the measurements. As mentioned before "exposure to UFPs arising from building activities may have different effect on both public health and the environment than UFP arise from combustion". Consequently, for an efficient risk assessment and management, the ecotoxicity and the environmental behaviour of UFPs arising from building activities should also be investigated as thoroughly as of UFP evolving from combustion or engineered processes. In future these investigations might influence environmental regulation.

\section{ASSOCIATED CONTENT}

615 Please see Figures S.1 to S.5 in supporting information.

\section{ACKNOWLEDGEMENT}

The authors thank Mr. Prasana Kunapalan, Mr. Fred Auckland, Mr. Thomas Pagkalis and Mr. Rex Packiyarajah for their help during the laboratory experiments. PK also thanks Drs. Hong Chen and Vina Kukadia from the Building and Research Establishment (BRE), UK, for providing BRE pollution guide.

\section{REFERENCES}

623 Andronache C, Gronholm T, Laakso L, Phillips V, Venalainen A (2006) Scavenging of ultrafine particles by rainfall at a boreal site: observations and model estimations. Atmos Chem Phys 6: 4739-4754 workplaces. Toxicol 269: 120-127 
Brouwer D, van Duuren-Stuurman B, Berges M, Jankowska E, Bard D, Mark D (2009) From workplace air measurement results toward estimates of exposure? Development of a strategy to assess exposure to manufactured nano-objects. J Nanopartcle Res 11: 1867-1881

Brouwer DH, Gijsbers JHJ, Lurnvink MWM (2004) Personal Exposure to Ultrafine Particles in the Workplace: Exploring Sampling Techniques and Strategies. Ann Occup Hyg 48: 439-453

BS EN 12390-2:2009 (2009) Testing hardened concrete. Making and curing specimens for strength tests. ISBN 9780580670688

BS EN 12390-3:2009 (2009) Testing hardened concrete. Compressive strength of test specimens ISBN 9780580587979

BS EN 12390-4:2000 (2000) Testing hardened concrete. Compressive strength. Specification for testing machines ISBN 0580354008

Buonanno G, Morawska L, Stabile L (2009) Particle emission factors during cooking activities. Atmos Environ 43: 3235-3242

Bystrzejewska-Piotrowska G, Golimowski J, Urban PL (2009) Nanoparticles: Their potential toxicity, waste and environmental management. Waste Manage 29: 2587-2595

Carpentieri M, Kumar P (2011) Ground-fixed and on-board measurements of nanoparticles in the wake of a moving vehicle. Atmos Environ 45: 58375852

COSHH (2005) Control of substances hazardous to health (Fifth edition). The Control of Substances Hazardous to Health Regulation 2002 (as amended) Approved code of practice and guidance L5, HSE Books, ISBN 978970 717629817177.

de Hartog JJ, Hoek G, Mirme A, Tuch T, Kos GPA, ten Brink HM, Brunekreef B, Cyrys J, Heinrich J, Pitz M, Lanki T, Vallius M, Pekkanen J, Kreyling WG (2005) Relationship between different size classes of particulate matter and meteorology in three European cities. J Environ Monit 7: 302-310

Dorevitch S, Demirtas H, Perksy VW, Erdal S, Conroy L, Schoonover T, Scheff PA (2006) Demolition of high-rise public housing increases particulate matter air pollution in communities of high-risk asthmatics. J Air Waste Manage Assoc 56: 1022-1032

Fuller G, Carslaw DC, Lodge HW (2002) An empirical approach for the prediction of daily mean PM10 concentrations. Atmos Environ 36: 14311441

Fuller GW, Green D (2004) The impact of local fugitive PM10 from building works and road works on the assessment of the European Union Limit Value. Atmos Environ 38: 4993-5002

Hansen D, Blahout B, Benner D, Popp, W (2008) Environmental sampling of particulate matter and fungal spores during demolition of a building on a hospital area. J Hosp Infect 70: 259-264

Harrison RM, Beddows DCS, Dall'Osto M (2011) PMF analysis of wide-range particle size spectra collected on a major highway. Environ Sci Technol 45: $5522-5528$

HSE (2006) The assessment of different metrics of the concentration of nano (ultrafine) particles in exisiting and new industries. Health and Safety Executive Research Report RR513, pp. 72.

HSE (2010) Dust control on cut-off saws used for stone or concrete cutting. Health and Safety Executive Construction Information Sheet No 54 (Revision 1), 1-4. 
ILO (1995) Safety, health and welfare on construction sites: A training manual. International Labour Organization ISBN 92-2-109182-1, pp. 134.

Kittelson DB (1998) Engines and nano-particles: a review. J Aerosol Sci 29: 575588

Knibbs LD, Cole-Hunter T, Morawska L (2011) A review of commuter exposure to ultrafine particles and its health effects. Atmos Environ 45: 2611-2622

Kuhlbusch T, Asbach C, Fissan H, Gohler D, Stintz M (2011) Nanoparticle exposure at nanotechnology workplaces: A review. Part Fibre Toxicol 8: 22

Kukadia V, Upton S, Grimwood C (2003) Contorlling particles, vapour and noise pollution from construction sites; Part 2: Site Preparation, demolition, earthworks and landscaping. BRE Pollution Guide, 1-8.

Kumar P, Fennell P, Britter R (2008a) Measurements of particles in the 5-1000 $\mathrm{nm}$ range close to road level in an urban street canyon. Sci Total Environ 390: 437-447

Kumar P, Fennell P, Langley D, Britter R (2008b) Pseudo-simultaneous measurements for the vertical variation of coarse, fine and ultra fine particles in an urban street canyon. Atmos Environ 42: 4304-4319

Kumar P, Fennell P, Symonds J, Britter R, (2008c) Treatment of losses of ultrafine aerosol particles in long sampling tubes during ambient measurements. Atmos Environ 42: 8819-8826

Kumar P, Fennell P, Hayhurst A, Britter RE (2009) Street versus rooftop level concentrations of fine particles in a Cambridge street canyon. BoundaryLayer Meteorol 131: 3-18

Kumar P, Fennell P, Robins A (2010a) Comparison of the behaviour of manufactured and other airborne nanoparticles and the consequences for prioritising research and regulation activities. J Nanopartcle Res 12: 15231530

Kumar P, Robins A, Vardoulakis S, Britter R (2010b) A review of the characteristics of nanoparticles in the urban atmosphere and the prospects for developing regulatory controls. Atmos Environ 44: 5035-5052

Kumar P, Gurjar BR, Nagpure A, Harrison RM (2011a) Preliminary estimates of nanoparticle number emissions from road vehicles in megacity Delhi and associated health impacts. Environ Sci Technol 45: 5514-5521

Kumar P, Ketzel M, Vardoulakis S, Pirjola L, Britter R (2011b) Dynamics and dispersion modelling of nanoparticles from road traffic in the urban atmospheric environment - a review. J Aerosol Sci 42: 580-603

Kumar P, Robins A, Vardoulakis S, Quincey P (2011c) Technical challenges in tackling regulatory concerns for urban atmospheric nanoparticles. Particuology 9: 566-571.

Kumar P (2011d) Footprints of airborne ultrafine particles on urban air quality and public health. J Civil Environ Eng 1:e101: doi:10.4172/jcee.1000e4101.

Mann S (2006) Nanotechnology and construction. Nanoforum Report. Institute of nanotechnology, Stirling.

McDonald PJ, Aptaker PS, Mitchell J, Mulheron M (2007) A unilateral NMR magnet for sub-structure analysis in the built environment: The Surface GARField. J Magn Reson 185: 1-11

McGarry P, Morawska L, He C, Jayaratne R, Falk M, Tran Q, Wang H (2011) Exposure to Particles from Laser Printers Operating within Office Workplaces. Environ Sci Technol 45: 6444-6452

Morawska L, Ristovski Z, Jayaratne ER, Keogh DU, Ling X (2008) Ambient nano and ultrafine particles from motor vehicle emissions: Characteristics, 
ambient processing and implications on human exposure. Atmos Environ 42: 8113-8138

Nazari A, Riahi S (2011) Splitting tensile strength of concrete using ground granulated blast furnace slag and $\mathrm{SiO} 2$ nanoparticles as binder. Energ Buildings 43: 864-872

Nowack B, Bucheli TD (2007) Occurrence, behavior and effects of nanoparticles in the environment. Environ Pollut 150: 5-22

Park K, Cao F, Kittelson DB, McMurray PH (2003) Relationship between particle mass and mobility for diesel exhaust particles. Environ Sci Technol 37: 577583

Sanchez F, Sobolev K (2010) Nanotechnology in concrete - A review. Constr Build Mater 24: 2060-2071

Schneider T, Brouwer DH, Koponen IK, Jensen KA, Fransman W, Van DuurenStuurman B, Van Tongeren M, Tielemans E (2011) Conceptual model for assessment of inhalation exposure to manufactured nanoparticles. J Expos Sci Environ Epidemiol 21: 450-463

The Stationary Office (1974) Health and Safety at Work etc Act. Ch37, ISBN 010543774

Tjoe Nij E, Hilhorst S, Spee T, Spierings J, Steffens F, Lumens M, Heederik D (2003) Dust Control Measures in the Construction Industry. Ann Occup Hyg 47: 211-218

Wallace L, Ott W (2011) Personal exposure to ultrafine particles. J Expos Sci Environ Epidemiol 21: 20-30 


\section{LIST OF FIGURE CAPTIONS}

756 Figure 1. PNDs averaged over the crushing durations of concrete cubes having 757 different compressive strengths. Also are shown percent increase in PNCs after 758 adjusting for background in the 5-100, 100-300 and 300-562 $\mathrm{nm}$ size ranges.

759 Figure 2. Temporal changes in the PNCs during the demolition of concrete (a) 760 slab-1, and (b) slab-2, and corresponding changes in average PNDs during 761 various stages of demolition process for concrete (c) slab-1, and (d) slab-2.

762 Figure 3. Temporal evolution of PNCs during (a) "dry" and (b) "wet" recycling 763 of concrete. Also are shown corresponding mean PNDs during (c) "dry" and (d) 764 "wet" recycling of concrete.

765 Figure 4. The net PMDs during the cube crushing, slab demolition, "dry" and 766 "wet" recycling processes. The net PMDs reflect new release of particle mass in 767 various size range since these are obtained by subtracting the background PMDs 768 (during no-work) from the total PMDs recorded during the event (during work) 769 time.

770 Figure 5. Release of new particle number and mass concentrations from different 771 building activities. These are estimated by subtracting the background 772 concentrations. 


\section{LIST OF TABLES}

Table 1. Mix design data for mixes M1, M2 and M3.

\begin{tabular}{llll}
\hline Mix Designation & M1 & M2 & M3 \\
\hline Strength Grade $^{\mathrm{a}}$ & $\mathrm{C} 35 / 45$ & $\mathrm{C} 30 / 37$ & $\mathrm{C} 25 / 30$ \\
\hline${\text { Cement }\left(\mathrm{kg} \mathrm{m}^{-3}\right)}^{20 \mathrm{~mm} \text { aggregate }}\left(\mathrm{kg} \mathrm{m}^{-3}\right)$ & 689 & 677 & 660 \\
\hline $10 \mathrm{~mm}^{\text {aggregate }}\left(\mathrm{kg} \mathrm{m}^{-3}\right)$ & 339 & 333 & 325 \\
\hline Sand $^{\mathrm{b}}\left(\mathrm{kg} \mathrm{m}^{-3}\right)$ & 803 & 789 & 770 \\
\hline Free water $\left(\mathrm{kg} \mathrm{m}^{-3}\right)$ & 154 & 172 & 188 \\
\hline Free Water/Cement ratio & 0.44 & 0.50 & 0.56 \\
\hline
\end{tabular}

${ }^{a}$ Indicates characteristic strength (MPa) at 28 days measured using cylinder and cube specimens.

${ }^{\mathrm{b}}$ In saturated, surface-dry condition. 
Click here to download Figure: Fig. 1_PND_Crushing of conrete cubes.ppt

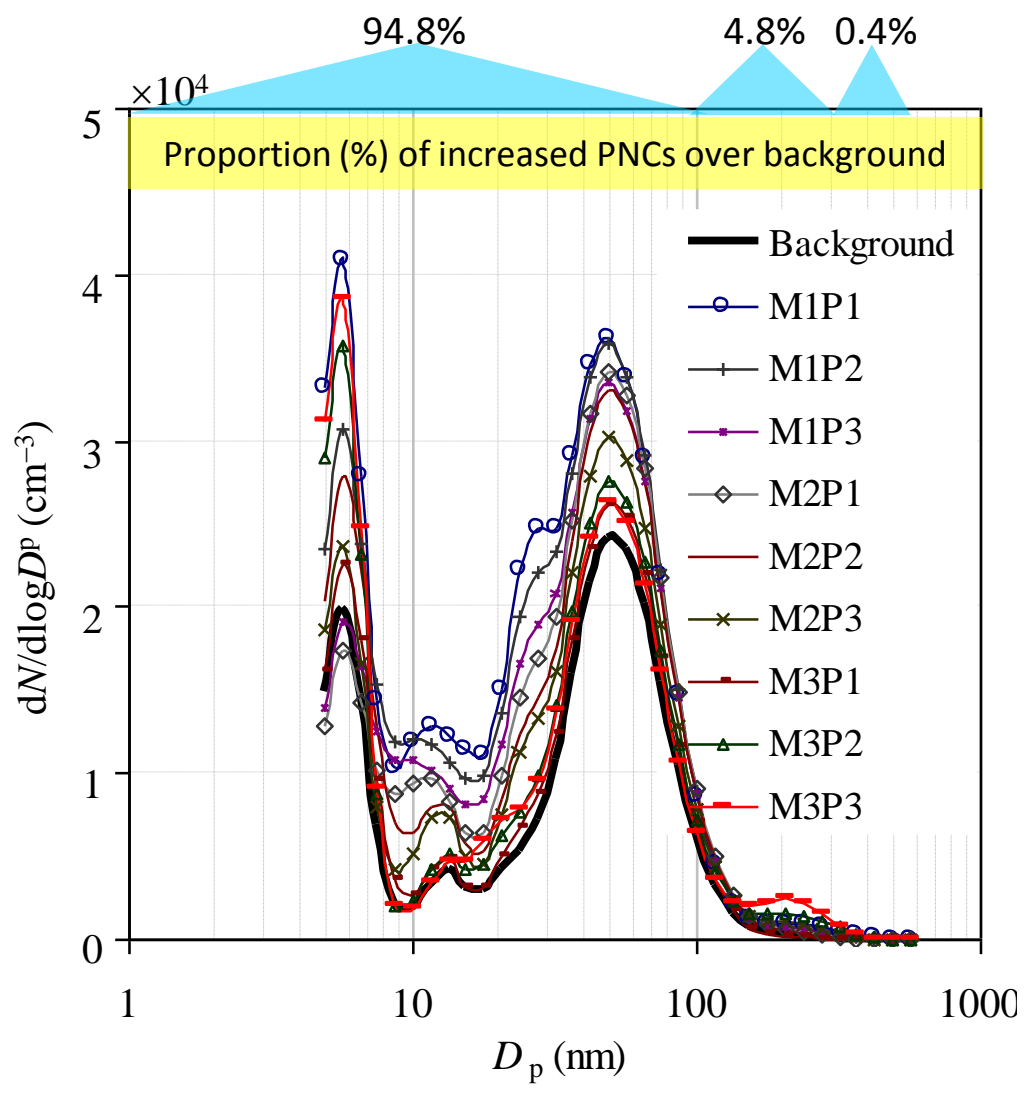


Click here to download Figure: Fig. 2_PND \& PNC_Slab demolition.ppt
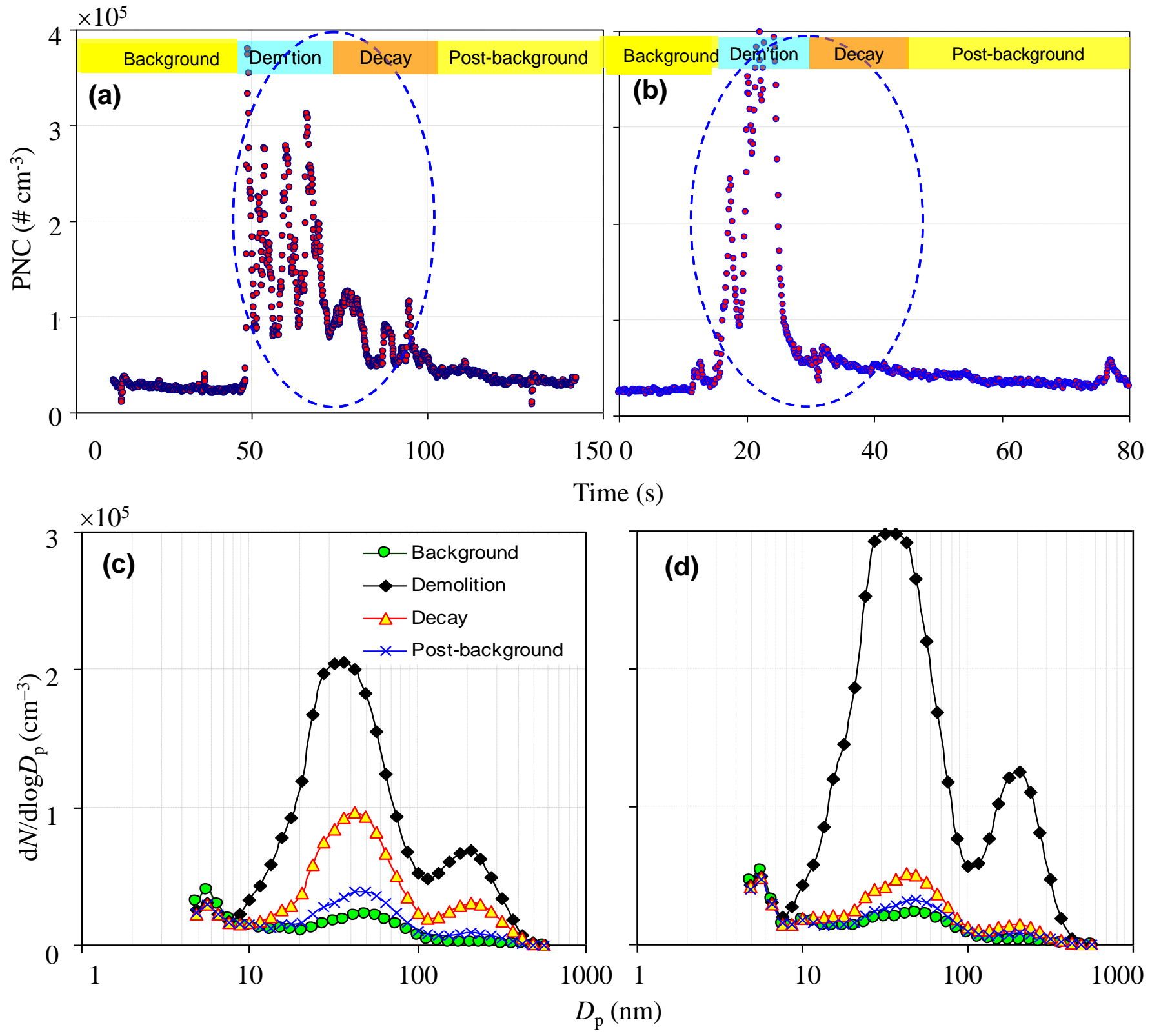
Click here to download Figure: Fig. 3_PND \& PNC_Recycling.ppt
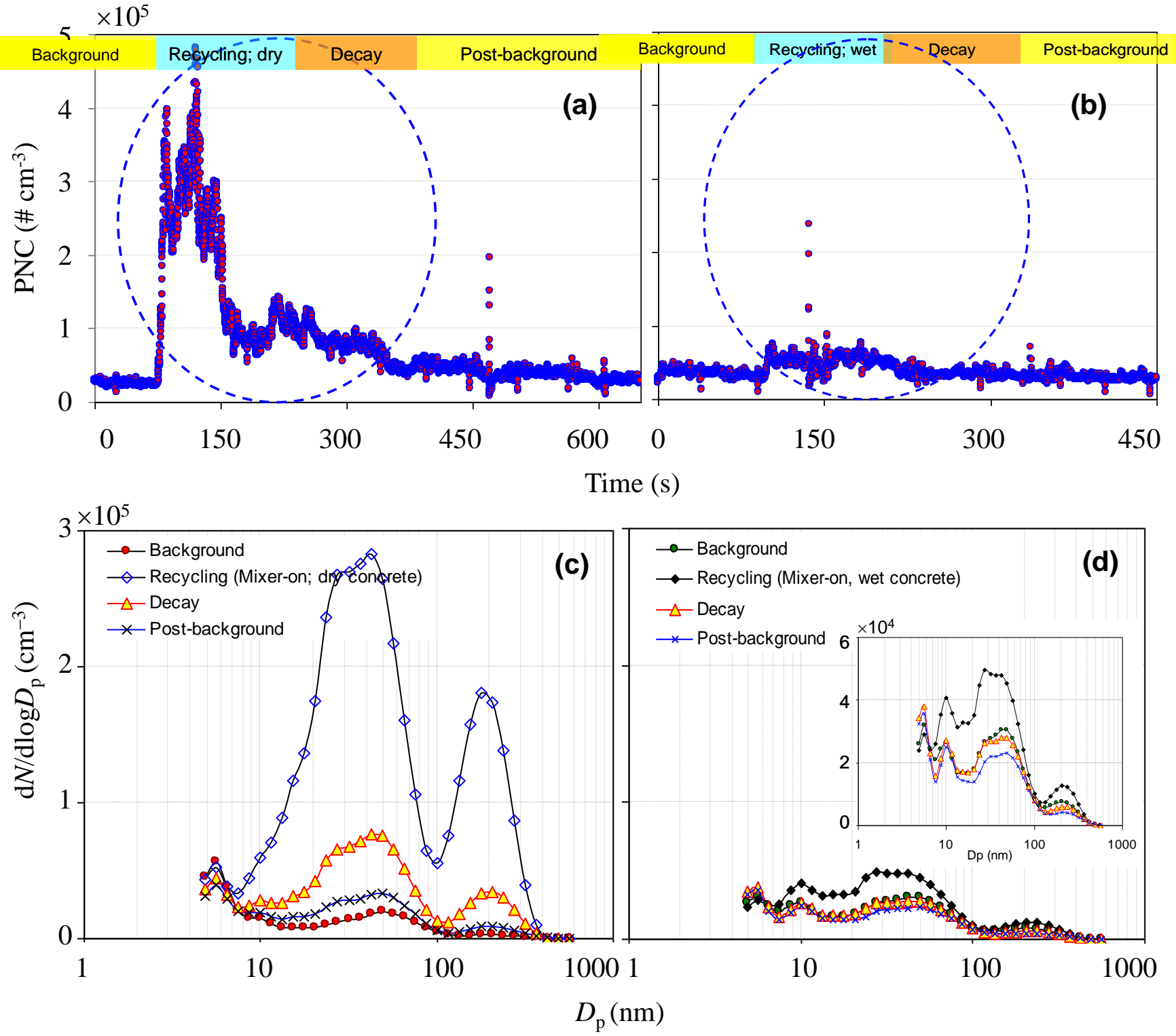
Click here to download Figure: Fig. 4_Net PMDs.ppt

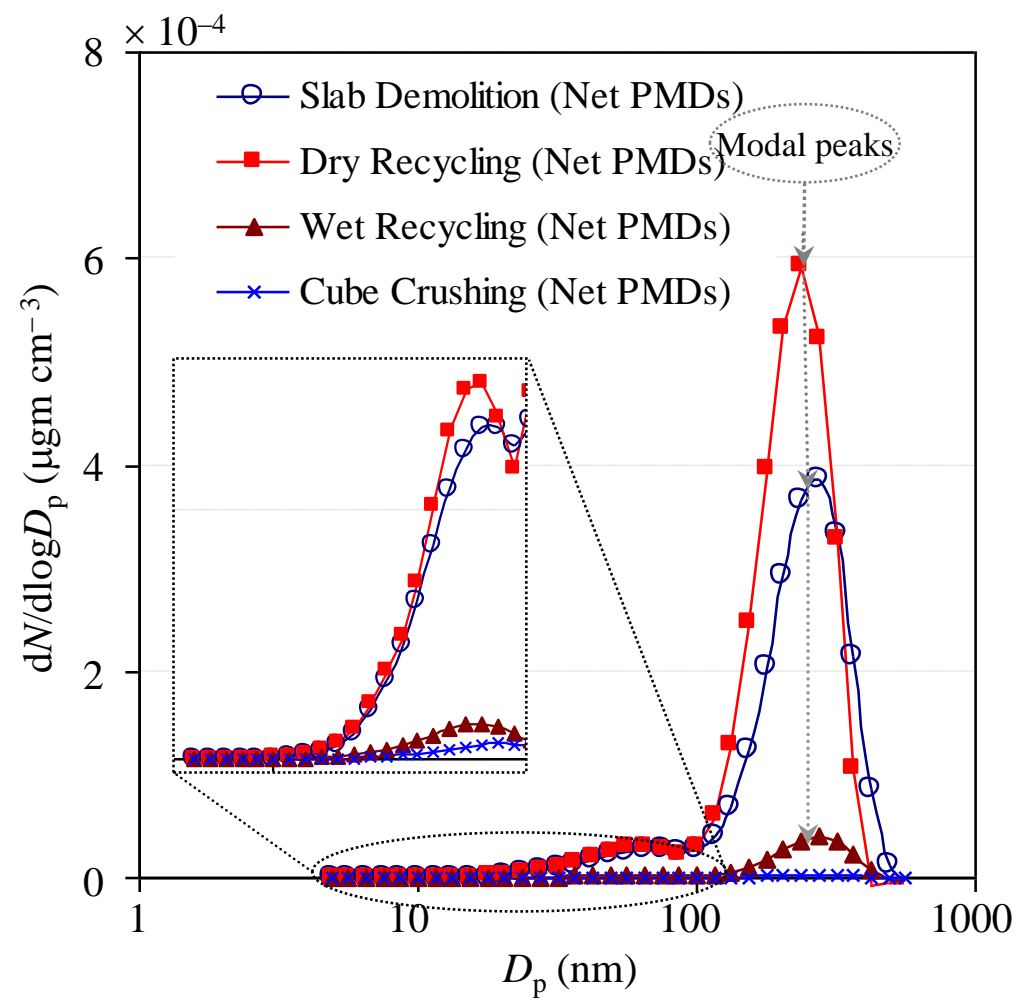


Click here to download Figure: Fig. 5_PMCs and PNCs.ppt

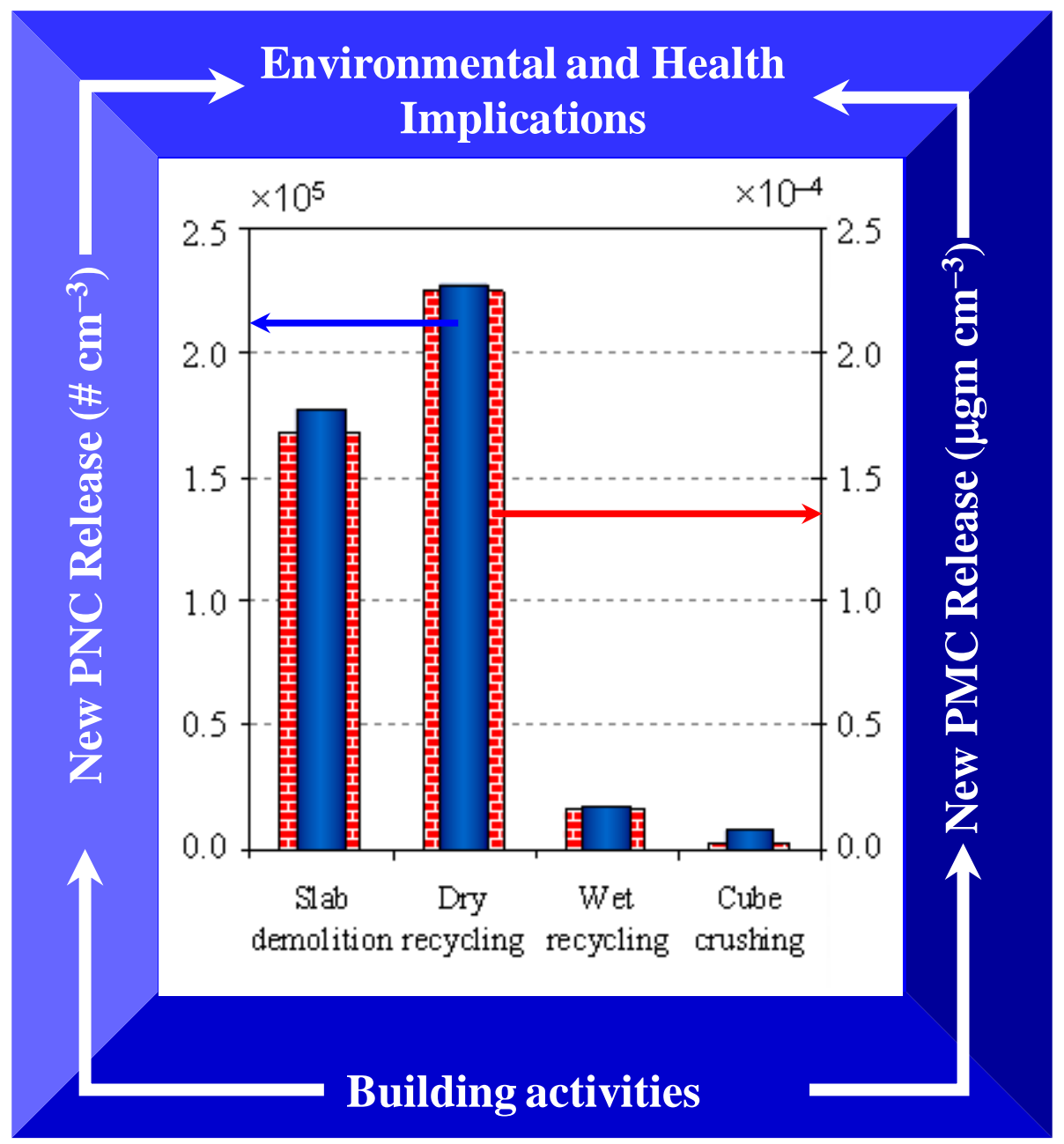

